\title{
Sustainable travel behaviour and the widespread impacts on the local economy
}

\section{Candice C Howarth}

Global Sustainability Institute, Anglia Ruskin University, United Kingdom

Polyvios Polyviou

Transport for All, United Kingdom

Corresponding author

Candice Howarth, Global Sustainability Institute, Anglia Ruskin University, East Road, Cambridge CB1 1PT, United Kingdom.

Email: Candice.howarth@anglia.ac.uk

\begin{abstract}
Statistics show that unsustainable travel behaviour and global greenhouse gas emissions are growing and due to the perceived indispensable nature of personal travel, shifts to more sustainable modes remain a challenge. Automobility supports sustained local economic growth but also raises issues around safety, health, road fatalities, traffic and congestion and detrimental environmental impacts. This paper addresses the issue of sustainable mobility by investigating how to increase sustainable travel choices and, where this is not possible, ensure existing travel choices and
\end{abstract}


patterns are as environmentally-friendly as possible. Existing soft initiatives aimed at increasing sustainable travel behaviour fail to fully acknowledge that travel decisions are made at the individual level and that tailored strategies would be more effective at targeting distinct behavioural patterns. Influencing changes in travel behaviour at the local level demonstrates significant potential where individual behaviour can be influenced if appropriate support at the system level is in place and complies with the needs of individuals. This paper demonstrates that, in doing so, this will simultaneously address other areas, such as accessibility, employability, health and sustainable growth, crucial to the establishment and survival of automobility by both supporting local economic growth and achieving reductions in Carbon emissions.

\section{Key words}

Travel behaviour, sustainability, travel choices, systemic change

\section{Introduction}

Much of local economic growth relies on the transport sector for addressing issues of accessibility, health, geographical disparity, employment, technological development and mobility, yet it contributes significantly to local (e.g. air pollution) and global (e.g. climate change) environmental issues. Whilst automobility encompasses the automobile system, car cultures and processes that revolve around them, the sector can play a crucial role in delivering sustainability (in terms of 
impacts and processes) at the local and global levels. This paper looks at the behavioural dimension of automobility and seeks to address the following question: in a time where sustainability covers environmental, economic and societal growth, how can sustainable travel behaviour be achieved whilst maintaining the prominent role held by automobility? This focuses particularly on two areas: (i) the extent to which people can be encouraged to reduce their travel by car and take up more sustainable travel choices, and (ii) when the above is not possible, how can individuals be encouraged to adopt sustainable practices within their travelling choices (e.g. adopting sustainable driving patterns to reduce environmental impact). This paper focuses on sustainable travel behaviour at the individual level and addresses the need for compliance between the 'system' (or local economic model) and individual travel needs.

Over the last 100 years there has been a revolution in personal travel, primarily associated with the growth in car ownership with the UK having the highest rate of car dependency and lowest public transport mode share within the EU (Commission for Integrated Transport, 2006). Car dependency is high and mainly attributed to the fact that, over the past decade, the costs of public transport alternatives have risen in real terms while the costs of motoring have fallen, in addition, car owner's misperceptions of the real costs of their motoring have further increased this dependency. More specifically, vehicle excise duty, insurance, servicing and depreciation are all fixed costs which, once paid, tend to be forgotten; thus, when comparing alternatives to car use for a specific journey many motorists only consider the cost of fuel. Motorists are also often unaware of how big an impact car usage has and how far-reaching those impacts might be. The costs to society of existing car-dependent transport patterns incorporate the costs of transport and extend to almost every 
sector of people's lives. In the past, congestion was thought to represent the majority of transport's external costs to society but these in fact extend to the costs of accidents, air quality, physical inactivity, greenhouse gas (GHG) emissions and noise, estimated at £27-38 billion per annum (The Cabinet Office, 2009a). Nevertheless access to transport enables increased connectivity, access to work, leisure and services and the transport sector itself employs thousands of people. A vicious circle is inevitable when planning decisions and land-use patterns change to reflect car-dependent lifestyles with shops and services moving to car-dependent locations. This often results in the need for longer journeys leading to increased accessibility issues for those with limited or no access to a car as well as implications for employment opportunities, with up to two out of five jobseekers citing an inadequate or expensive transport system as a barrier to getting a job (Social Exclusion Unit, 2003).

The 2006 Eddington Transport Study (DfT, 2006) stated that a high-performing transport system is essential to encourage and maintain economic growth and highlights the need for transport policy to be aligned with economic growth, transport infrastructure and transport demands. In light of increasing travel demand and rising GHG emissions, behaviour change incorporated into a holistic and systemic approach can facilitate a switch to more sustainable practices and address the array of detrimental issues associated with a local transport system (Avineri and Goodwin. 2010). A holistic approach is needed to address issues at the local level where changes in travel behaviour can have a sustained positive impact on the economy. UK policies currently reflect a disconnected approach to transport issues which nonetheless have core underlying similarities; these could be addressed simultaneously through a locally-based behaviour strategy to overcome unsustainable 
travel and consequently contribute to resolving a variety of issues such as the high costs of congestion to urban areas (Cabinet Office, 2009b).

Current travel behaviour is unsustainable: people are travelling further and for longer, car ownership has increased while car occupancy has dropped, and the perceived indispensable nature of cars combined with habitual car use means that cost is not a strong deterrent of car use, it is crucial therefore to identify alternative ways to encourage changes in travel behaviour (DfT, 2009). Stradling (2003) identified a trend among individuals who stated that as much as $40 \%$ of their car journeys could be reduced and as many as $80 \%$ could be replaced simply by maximising the use of alternative means of transport. There is therefore significant potential to optimise adoption of sustainable travel choices. However, with high car production (Society of Motor Manufacturers and Traders, 2009) and lenient manufacturer restrictions on new vehicle emissions (European Federation for Transport and Environment, 2007), the need for reduced unsustainable private travel and adoption of more sustainable driving practices is growing. The sustainability of transport therefore relies on, where possible, increasing sustainable choices (Table 1), the increased use of environmentally-friendly modes and on reducing overall demand for transport.

\section{Training and awareness}

- Direct feedback: measurements of emissions from car shown to driver

- Driver training: environmental awareness training during driving education

- Promotion of on-board technologies: equipment to identify and report problems to the driver; information systems to assist drivers in maximising fuel economy; automated systems to improve fuel economy by maintaining certain vehicle functions

Demand reduction 


\begin{tabular}{|c|c|}
\hline & $\begin{array}{l}\text { Congestion pricing and toll rings to increase public acceptance by using revenue } \\
\text { to fund infrastructure funding } \\
\text { Workplace parking charges } \\
\text { Carpooling } \\
\text { Tele-working } \\
\text { Fuel price increase } \\
\text { Video conferencing } \\
\text { Workplace travel plans }\end{array}$ \\
\hline \multicolumn{2}{|c|}{ Individualised marketing } \\
\hline & $\begin{array}{l}\text { Schemes providing tailored information } \\
\text { Only small behavioural changes required (i.e. modal shift just twice a week) } \\
\text { Encourages people to participate } \\
\text { Increases feeling of personal action and involvement }\end{array}$ \\
\hline \multicolumn{2}{|c|}{ Attitude and behavioural shifts } \\
\hline & $\begin{array}{l}\text { Flexible working: tele-working and teleconferencing } \\
\text { Travel planning services } \\
\text { Car sharing schemes } \\
\text { Information provision } \\
\text { Co-modality } \\
\text { Integrating different modes of transport } \\
\text { Travel blending }\end{array}$ \\
\hline \multicolumn{2}{|c|}{ Standards, taxation } \\
\hline & $\begin{array}{l}\text { Fuel efficiency standards } \\
\text { Sliding scale tax on vehicles (Vehicle Excise Duty) - to encourage purchase of } \\
\text { environmentally friendly cars based on } \mathrm{CO}_{2} \text { emissions } \\
\text { Carbon fuel tax to reduce congestion and } \mathrm{CO}_{2} \text { emissions } \\
\text { Vehicle labelling providing more information on environmentally-friendly options } \\
\text { as well as } \mathrm{CO}_{2} \text { and fuel efficiency } \\
\text { Parking charges } \\
\text { Vehicle ownership taxes } \\
\text { Reduce impacts (visual, audio, health) of transport on environment }\end{array}$ \\
\hline
\end{tabular}

Table 1. Suggestions for increasing the sustainability of road travel (Howarth and Ryley, 2012).

Whilst this is essential, it would be imprudent to assume that all travel can be changed as the process of decision-making in the context of travel choices in particular is complex: individuals 
make different choices based on different predispositions whilst, simultaneously individuals will make different choices even if they share the same predispositions. It is therefore necessary to address travel patterns at different stages of a traveller's internal decision-making process (whether conscious or not), when take up of alternative means does not always occur and can be influenced by a number of variables (Table 2).

\begin{tabular}{|l|l|l|}
\hline Before a journey & During a journey & After a journey \\
\hline$\bullet$ Necessity of trip & $\bullet$ Choice of route & $\bullet$ Feedback system \\
- Choice of travel mode & $\bullet$ Choice of time & $\bullet$ Information provision \\
- Travel blending & $\bullet \begin{array}{l}\text { Choice of } \\
\text { departure/destination }\end{array}$ & \\
$\begin{array}{l}\text { Purchase vehicle with low } \\
\text { Carbon emissions }\end{array}$ & $\bullet$ Driving style & \\
Combined use of several & & \\
\hline
\end{tabular}

Table 2. Issues arising in the decision-making process of a traveller. These three stages provide an opportunity at which information can be used to increase awareness on all options available are each unique in their usefulness at tackling different areas of unsustainable travel behaviour. From Knudsen (2007).

The UK has a target to reduce $\mathrm{CO}_{2}$ emissions by $60 \%$ below 1990 levels by 2050 (Environmental Audit Committee, 2006) and with road transport contributing to a quarter of UK emissions (DTI, 2005), local authorities have a key role to play. Local effort has seen the implementation of initiatives which contribute towards global climate change and therefore the local economic system plays a central role in the prevention and adaptation to anthropogenic climate change locally (Bulkeley and Kern, 2006). Whilst the NI 1888 National Directive, designed to advise local 
authorities on how to manage risks and opportunities presented by climate change and implement an adaptation strategy (Defra, 2010) was effective in encouraging a holistic approach to sustainability on a local level, local road authorities in particular were under high pressure to reduce their emissions. In spite of this, central reporting through the National Indicator set ceased in 2010 with Defra advising Local Authorities to utilise the Directives as a guidance tool. Addressing the unsustainable nature of travel behaviour is central to local mitigation of and adaptation to climate change and thus provides significant benefits to local economic growth (DfT, 2011).

\section{Options for sustainability and impacts to the local economy}

The EU 's 2050 White Transport Paper, "Roadmap to a Single European Transport Area - Towards a competitive and resource efficient transport system", presents key facts and figures about transport in Europe and sets goals for urban transport to shift substantially to cleaner vehicles and fuels, halving the use of 'conventionally-fuelled' cars in urban transport by 2030 , phasing them out in cities by 2050 with a shift to electric cars, hydrogen cars, hybrid cars, increased public transport, walking and cycling in cities. This would ultimately lead to $\mathrm{CO}_{2}$-free city logistics in major urban centres by 2030 (European Commission, 2011). The UK's 2011 White Transport paper describes its vision for transport as an engine for economic growth whilst simultaneously addressing issues such as safer and greener communities (DfT, 2011); it encourages the use of public and active forms of travel, particularly for short trips, and where behaviour change alone is insufficient, the introduction of electric vehicles. Local action, the paper states, is elementary to the implementation of local 
sustainable strategies, and as a result local governments are being urged to take a more active role in the implementation of sustainable travel schemes.

The UK Sustainable Development Commission (SDC) states that $84 \%$ of total trips in the UK are journeys of less than 10 miles, indicating the huge potential for public transport (UK Sustainable Development Commission, 2010), particularly buses which represent $64 \%$ of total passenger journeys on public transport in England (Department for Transport, 2009). The transport industry itself represents an important part of economic development where it directly employs 10 million people in the EU and accounts for 5\% of GDP (European Commission, 2011). There is therefore a need to take decisive policy action and address issues within public transport systems by implementing more innovative strategies such as Intelligent Transport Systems and dynamic bus fleet management (Polyviou, Hounsell and Shretha, 2012) to increase the overall quality, reliability and attractiveness of public transport available to the public. With travel demand increasing substantially, a low-carbon transportation system requires improvement in all it's dimensions: travel demand, mode choice, and technology (Bongardt, Breithaupt and Creutzig, 2010). Consequently, there is a need for efficient, inter-modal freight transport and smart urban logistics, advanced fuel and car technologies and high quality alternatives to individual car-use, providing an efficient public transport service and non-motorized transport infrastructure.

A sustainable transport system can have direct positive impacts on the local economy and society overall as it is very closely connected to employment, health and poverty. The Leonard Cheshire 
2007 Disability Review found that $67 \%$ of disabled people would use public transport more often if it were more accessible (LCD Review, 2007) and the 'Disability Poverty in the UK' report (LCD, 2008) shows that a lack of access to public transport can contribute to every aspect of disability poverty. $17.9 \%$ of individuals in the UK are below the poverty line (Wood and Grant, 2011) and the poverty gap between disabled and non-disabled people is widening with $34 \%$ of disabled people living in low income households, compared to $17 \%$ of non-disabled people (Gore and Parckar, 2009). This gap is indicative of the extent to which disabled people continue to encounter multiple barriers (including physical inaccessibility to public transport options) to equality in the field of employment. . Carr, Lund, Oxley et al. (1994) state that the annual cost of excluding disabled people from public transport in the UK could be as high as one billion pounds per year, based on additional costs to the economy of providing health care services at home (e.g. chiropody, GP visits), special transport to health and social care services and loss of tax revenue from people who are unable to access employment. Inaccessible transport therefore has a detrimental impact on employment and economic security: $23 \%$ of disabled people have had to refuse a job offer because of inaccessible transport, a further $23 \%$ have had to decline a job interview and $48 \%$ are reported to have restricted their choice of job selection for the same reason (Gore and Parckar, 2010).

Sustainable travel choices, notably mode switching or increased walking or cycling also have demonstrable health impacts: adults who are active have a $20-30 \%$ reduced risk of premature death (Davis and Cavill, 2005) and on average, walking to and from public transport can contribute towards $66 \%$ of the recommended daily level of moderate physical activity necessary to promote good health (Douglas, Thomson, Jepson et al., 2007; Besser and Dannenberg, 2005; Gorman, 
Douglas, Conway et al., 2003). The benefits of increasing sustainable travel behaviour are widespread and can have an observable and longstanding impact to the long-term sustainability of local economic development.

\section{The role of behaviour change for sustainable mobility}

Why behaviour change?

A fundamental human need for mobility ultimately drives the demand for travel; but it also has an intrinsic positive utility and is valued both for its necessity and recreational qualities, not just for being a means to reach a destination. Consequently changing travel behaviour is not just a question of encouraging modal shifts, this requires a deep understanding of psychological processes that lead to travel behaviours in the first place. As well as the interactions of multiple elements taking place as described above, a variety of additional external factors intervene resulting in the complex nature of travel behaviour. Issues such as habitual behaviour, reluctance to change, perceptions of travel mode, cost of alternative options, travel time, travel purpose, number of passengers, comfort, convenience and so forth all play a key role in influencing behaviour. The formation of travel behaviour is driven by the amalgamation of awareness, beliefs, norms, behaviour controls, attitudes and intentions, yet good intentions often to do not result in corresponding behaviours (Howarth and Ryley, 2012). The Theory of Planned Behaviour states that attitudes and willingness to change alone do not lead to behaviour change but that social and psychological processes are linked to attitudes, subjective norms and perceived barriers to behaviour change 
(Ajzen, 1991). Howarth, Waterson, McDonald (2010) take this further by introducing additional social factors such as utility maximisation and a sense of environmentally-focussed moral obligation which have a significant influence all these elements especially when relating to travel behaviour.

Increasing sustainable travel choices can be facilitated through the means of appropriate infrastructure and economic tools however the extent to which this achieves long term sustained change is unclear. Adopting entire sustainable lifestyle changes can be perceived as unachievable and thus there is a need to encourage sustainable practices of 'locked' behaviours to ensure long term and sustained changes are achieved. Economic, political and technological measures are used to reduce transport's GHG emissions, however, although they are often implemented simultaneously, the linkages between all measures and their common goal are not often aligned or entirely transparent to the general public who ultimately will be making changes in their behaviour. Government policies can help incorporate sustainable transport growth and reduce per capita emissions by producing an infrastructure and economic model which facilitates and supports behaviour change and implementing economic measures such as taxes and charges which must visibly and realistically reflect the environmental costs of travelling. The impacts of these policies, as with those from technological innovations, can be uncertain (Greene and Wegener, 1997). They must fulfil specific requirements to ensure scalability and visibility of success, and are slow in implementation and visibility of impacts can be delayed for a time period following their implementation (Banister, Pucher and Lee-Gosselin, 2007). 
Schemes focussed on attitudinal and behavioural changes addressing travel choices and encouraging a shift towards sustainable practices (both voluntary and enforced) could demonstrate more immediate and long-lasting results specifically in terms of uptake of alternative transport options, consequent GHG emissions reductions resulting in increased public support, sustained changes and further opportunities for parallel schemes (Howarth, 2010 and Cairns, Sloman, Newson et al., 2008). Approaches targeted at altering specific behaviours, whilst simultaneously using existing political, technological and economic measures increase the likelihood of sustaining long-lasting emissions reductions (EEA, 2010). Single initiatives, whether fiscal, technological or legislative may offset $\mathrm{CO}_{2}$ emissions by 1 or $2 \%$ however, combining these with behavioural initiatives to reduce demand could result in savings of over 10\% (IEA, 2001).

\section{Evidence of successful behaviour change in achieving sustainable travel choices}

A variety of programmes have been implemented by addressing particular methods of communication and delivery such as reflections on personal travel, tailored travel feedback, personalised support, community outreach, social marketing and local government-based initiatives. These initiatives provide a range of examples of where the local economic model is aligned with the needs of travellers and where the provision of information in the form of mass and/or individual communication can provide a 'soft' approach to influencing behaviour change by facilitating the destabilisation of habits (Fujii and Gärling, 2007). Habits play a key part in inhibiting changes in travel behaviour and are at their weakest at specific points of transition in life (such as changing 
jobs, moving home etc) and voluntary behaviour change is more likely to occur when targeting this time (Howarth and Ryley 2012).

Specifically tailored travel feedback programmes in Japan (Fujii and Taniguchi, 2006) developed measures aimed at reducing $\mathrm{CO}_{2}$ emissions by increasing public transport and reducing car use through the provision of information on alternative travel options. Results highlighted that stated intentions to change travel behaviour were more likely to result in actual behaviour change when respondents were asked to provide a behavioural plan and details of the information they required to change their behaviour. Results from this type of personalised feedback planning showed a $19 \%$ reduction in $\mathrm{CO}_{2}$ emissions, $18 \%$ reduction in car use and a $50 \%$ increase in public transport use (maintained for a year following the end of the project). Research investigating the impact of information on alternative transport options (such as public transport, see Section on 'Options for sustainable travel'), combined with individuals engaged in reflecting on their own travel patterns and ways to change them resulted in an increase in public transport use (Taniguchi and Fujii, 2007). The provision of information alone is not sufficient to ensure behaviour change is maintained as decisions are also influenced by personalities, attitudes, norms, beliefs as well as and the degree of adequate support at the systems level to ensure travel choices are actually able to materialise; influencing voluntary travel behaviour change can be further enhanced by adhering to certain principles (Ampt, 2003), notably that change:

- Occurs according to existing lifestyles and values

- Occurs when there is a large range of options available 
- Is more likely to occur if the personal gain of doing so is clear and is perceived as easy

- Is more likely to occur if the impact achieved is clearly visible

- Is more likely to occur and be sustained if peer behaviour change is also evident

The IndiMark campaign (Brog, Erl and Mense, 2002), developed in Australia, Germany and the UK as a step-by-step procedure based on providing personal support and advice to encourage and motivate travel behaviour change. Its objective was to motivate people to think about their travel behaviour and increase the use of alternative options through incentives and increasing feelings of empowerment. It achieved an overall reduction in car use of 10\% (10\% in Brisbane and Perth, $9 \%$ in Gloucester and Frome, and 8\% in Vernheim), and although the same travel quota was recorded, the campaign achieved a change in mode use.

Additionally, the 'In Motion' community-based outreach program (Cooper, 2007) in Washington State (USA) aimed to reduce drive-alone travel and increase awareness on alternative modes through the use of commitments, prompts, incentives and by targeting social norms. Participants stated a drop in personal car use by $24-50 \%$ and an increase in public transport use by $20-50 \%$; whilst these variations are based on stated results they are indicative of the available scope for mode change at the individual level and willingness to adopt new travel patterns.

These different campaigns have achieved significant reductions in car use and increases in public transport use, however methods of monitoring mode usage are not always the same across different programmes. TAPESTRY (Travel Awareness Publicity and Education Supporting a 
Sustainable Transport Strategy) was a large integrated European project which investigated how information could influence travel behaviour (Transport and Travel Research Ltd, 2005). It aimed to (i) assess the effectiveness of travel awareness and information campaigns in encouraging European travellers to adopt more sustainable and multi-modal travel practices, and (ii) provide a set of recommendations on the potential of these campaigns and their cost effectiveness (DfT, 2005). It used the 5 stage model of behaviour change (Awareness, Acceptance, Attitudes, Action, Assimilation) as a basis and implementation of the campaigns in each of the case study areas centred around the 7 stage model: Awareness of problem, Accepting responsibility, Perception of options, Evaluation of options, Making a choice, Experimental Behaviour and Habitual behaviour. Results from the TAPESTRY case studies showed that awareness campaigns achieved significant shifts in attitudes and that these could lead to an increase in the use of sustainable transport modes and a decrease in car use (Transport and Travel Research Ltd, 2003).

More recent UK-based studies in Sutton (Smarter Travel Sutton: Transport for London, 2010) and Darlington, Peterborough and Worcester (Sustainable Travel Towns: Sloman, Cairns, Newson et al., 2010) also achieved a change in travel patterns by focussing on school and workplace travel planning, personal travel advice and information, advertising marketing campaigns, car clubs, car sharing schemes and strong brand identity. In the case of the Sustainable Travel Towns, detailed travel surveys, pedestrian, bus, cyclist and vehicle counts took place, and as a result, a reduction of car trips and distance travelled by car by $9 \%$ and $5-7 \%$ respectively per person were achieved as well as $10-22 \%$ increase in bus trips per person, an increase in $26-30 \%$ of cycling trips per head and a 13\% increase in walking on average across each town. The Smarter Travel Sutton campaign, 
whilst more focussed, achieved more noticeable changes in mode use: a $75 \%$ increase in cycle traffic was observed, $16 \%$ increase in bus patronage, a drop in car use by $3.2 \%$ lower than the baseline year of 2006 and walking increased to 22\% (up from 19.4\% in 2005/6). The dramatic increase in cycling trips consisted of an increase in new cyclists as well as an increase in cycling trips by habitual cyclists. The London borough of Sutton has one of the highest car ownership levels in London, with an existing cycle network and with $91 \%$ of its urban residents within $400 \mathrm{~m}$ of the nearest bus stop serving one or more of the existing 24 bus routes. This campaign presented an ideal opportunity to increase awareness of the existing transport and successfully maximise its usage.

There are numerous other examples of international programmes which show the value of sustainable transport to local economic growth demonstrating not only a need for such a shift but also the desirability and benefits of such schemes. The City of Ghent is 'making cycling normal' with subsidised student cycle schemes and distinct cycle paths; by prioritising this mode of active travel, the city has experienced a steady growth in terms of reduced congestion, increased access to the city centre, increased employment of the most vulnerable and through an innovative marketing campaign, engagement with local citizens. Norfolk-based Liftshare has increased car sharing for both work and leisure based journeys enabling a substantial reduction in Carbon emissions and journeys on the road. TaxiTub in Brittany, France provides an innovative network of taxis with the facilities to optimise the public transport system in rural areas by targeting individuals living in remote areas where bus journeys are low and journey times are high. 
These programmes highlight how a multi-faceted strategy combining increased awareness on alternative travel options, coordinated events to emphasise this, and active engagement with individuals demonstrated how stated intentions to change behaviour resulted in actual behaviour change. These campaigns are most successful when a person's intention to change behaviour is strong (Fujii and Taniguchi, 2006) and specific behaviours are targeted, yet they lack an attitudebased targeting of individuals whose intention to change may be low or non-existent. A gap therefore exists in the recognition that different people make different choices and decisions in terms of their travel behaviour for a variety of reasons and that, consequently, one single homogenous strategy, if successful, is unlikely to achieve long term change in all segments of the population. Identification of segmentation groups based on attitudinal characteristics specifically related to the nature of intentions to travel more sustainably is thereby needed. Combined messages around the benefits to the local economy can also increase a sense of ownership, responsibility and identity with the issue resulting in a range of spill-over effects such as unanticipated positive behaviour change, community engagement, long term shifts in travel behaviour change and so forth, all of which reinforce the positive benefits of shifts to sustainable travel practices to local economic growth.

The widespread availability and affordability of car travel has brought many benefits to many people with cars giving the freedom to travel to almost any destination, at whatever time the user wishes and with minimal need to plan ahead. They have made it easier to keep in touch with friends and family and to reach a wider range of job opportunities and as they have become more affordable, they have dramatically increased the travel possibilities available to ordinary families. The car has 
shaped towns and cities, changed landscapes and for many it has become an essential part of their lifestyle. However, for many people the growth of car-dependent lifestyles and the changes they have brought about have created serious problems. Local shops and services have moved further away, children's freedoms have been restricted due to dangers associated with roads, job locations can be difficult to access without a car, not having access to a car can lead to serious social exclusion, levels of noise and air pollution have increased, physical activity has dropped and carrelated accidents are the main cause of death for children. For car dependency to be controlled and sustainable transport modes to become more attractive, transport users need sustainable transport initiatives and incentives to encourage them. Most initiatives, however, lack detailed information on several aspects of the implementation phase and, as a result, it is difficult to relate the initiative's results to the geographical circumstances and transport organisations. Moreover, supporting policy measures, such as time-windows and vehicle restrictions for freight transport, are often considered unfair ways to keep City Distribution Centres alive. UK climate targets will not be met unless ministers ensure action at the local level plays its part in reducing emissions, and has the funds to do so. In London, specific cycling funding to the London boroughs has suffered and been abolished and consequently obtuse "corridor" and "neighbourhood" labels were introduced for allocation of funds allowing local councils to retreat entirely from making difficult choices around cycling, and focusing on general public improvements, that consequently have little effect on modal split.

\section{Audience and behaviour segmentation and a holistic approach to the 'system'}

Appropriate targeting for sustainable travel behaviour 
Results from Howarth, Waterson and McDonald (2010) identified key attitudinal and behavioural population segments appropriate for increasing adoption of sustainable travel behaviour. Participants were recruited through postal questionnaires in the first phase $(\mathrm{N}=902$, response rate: $18 \%)$ achieving a response rate similar to the rates obtained by Lorenzoni, Nicholson-Cole and Whitmarsh (2007). The sample obtained was representative of the UK population in terms of demographic and socio-economic characteristics as well as in terms of transport use, availability of public/private transport options (DfT/ONS, 2008) and views and concern towards climate change (Eurobarometer, 2011). Participants were also involved in focus group discussions to gain an insight into the perceived barriers to sustainable travel behaviour and gain an in depth understanding of how attitude and behaviour segmentation can facilitate sustainable automobility.

Results identified travel behaviour characteristics (mode use) and attitudinal traits (perceived ability, perceived usefulness, willingness, and knowledge of how to change travel behaviour) which determined the extent to which voluntary travel behaviour changes are possible. Variables such as age and awareness of sustainability issues also featured in the determination of the attitudinal and behavioural segmentations: Sustainably Aspiring Motorised Travellers (43.9\%) were environmentally-focused, felt morally responsible and obligated to change their travel behaviour yet they travelled principally by car. Sustainably Aspiring Active Travellers (29.8\%) were characterised by sustainable attitudes and marked active travelling (i.e. by non-motorised modes). Conversely Environmentally Apathetic Motorised Travellers (26.3\%) expressed little concern about the implications of their own personal behaviour and saw no point in changing it; this was further 
highlighted by their heavy motorised travelling patterns (Table 3). These groups are related to different perceptions of the barriers to behaviour change which were found to depend implicitly on perceived personal and social gains and losses.

\begin{tabular}{|c|c|c|}
\hline Awareness & Attitude & Behaviour \\
\hline $\begin{array}{l}\text { - Individuals believing in } \\
\text { human induced climate } \\
\text { change }(84.3 \%), \text { more likely } \\
\text { to be aged } 25 \text { to } 54 \text { years } \\
\text { old } \\
\text { - Individuals unsure of the } \\
\text { causes of climate change } \\
\text { ( } 8.2 \%), \text { more likely to } \\
\text { contain individuals aged } \\
\text { less than } 25 \text { and over } 54 \\
\text { - Individuals denying the } \\
\text { anthropogenic nature of } \\
\text { climate change ( } 7.5 \%), \\
\text { more likely to contain } \\
\text { individuals aged less than } \\
25 \text { and over } 54\end{array}$ & $\begin{array}{l}\text { - Sustainable Aspirers } \\
\text { (41.6\%): environmentally } \\
\text { focussed individuals with a } \\
\text { strong feeling of moral } \\
\text { responsibility and } \\
\text { obligation to change travel } \\
\text { behaviour } \\
\text { - Environmental Apathetics } \\
\text { ( } 58.4 \%) \text { individuals } \\
\text { showing little concern of } \\
\text { the implications of their } \\
\text { personal travel and who } \\
\text { see no point in changing it }\end{array}$ & $\begin{array}{l}\text { - Sustainable Aspiring } \\
\text { Motorised Travellers } \\
\text { (43.9\%) consisting of heavy } \\
\text { car using Sustainable } \\
\text { Aspirers } \\
\text { - Sustainably Aspiring Active } \\
\text { Travellers (29.8\%) } \\
\text { consisting of Sustainable } \\
\text { Aspirers who are } \\
\text { substantial non-motorised } \\
\text { mode users } \\
\text { - Environmental Apathetic } \\
\text { Motorised Travellers } \\
\text { (26.3\%) consisting of } \\
\text { Environmental Apathetics } \\
\text { who travel principally by car }\end{array}$ \\
\hline
\end{tabular}

Table 3. Key target audiences.

In order to overcome these perceived behavioural barriers and encourage sustainable travel behaviour locally therefore, initiatives promoting sustainable travel behaviour change will likely only be successful when they can be targeted and tailored to specific groupings and crucially conveyed within the direct context that individual travellers experience. The diverse nature of these groupings (Figure 1) and the identification of key, distinct characteristics (attitude, age, location, mode use) provide an excellent platform to target specific groups of people locally with information to overcome 
the attitude-behaviour gap and encourage sustainable travel choices and should this be met with resistance, the same medium should be used to influence sustainable driving patterns.

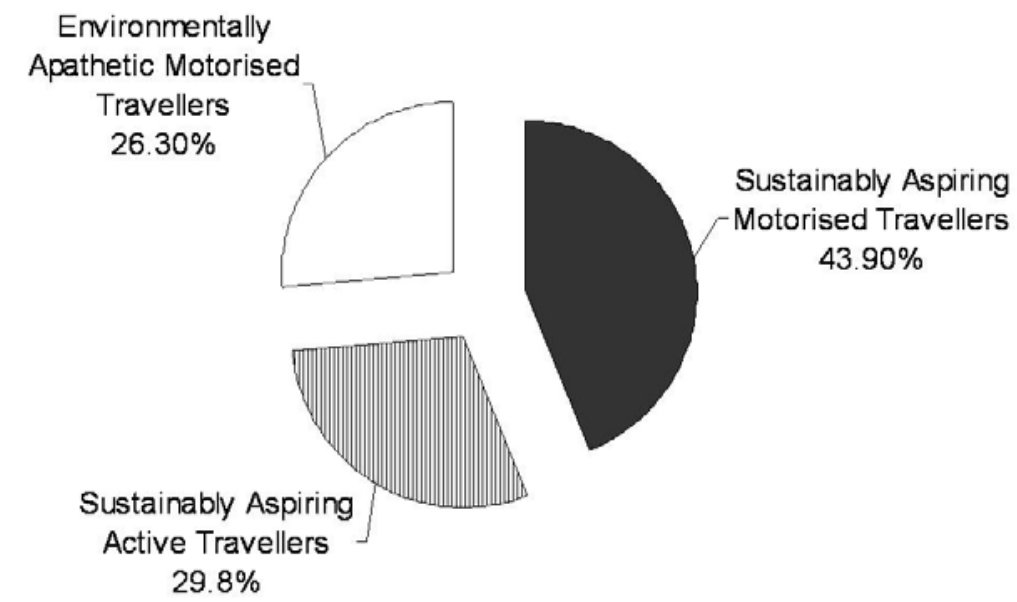

Figure 1. Behavioural - Attitudinal Groupings

The multi-faceted attitude-behaviour gap identified in existing research highlights the volatility of the formation of behaviours and that even unsustainable attitudes can lead to sustainable travel behaviour through indirect, external (i.e. alternative transport options) and internal (i.e. habit) factors. The identified and defined target groups are not exclusive and awareness packages should centre on a communal framework encompassing all audience requirements and subsequently tailored according to the targeted behaviour change. 
The distinction between each Behavioural grouping relates to attitudinal characteristic (Sustainable Aspirer or Environmental Apathetic) and principal mode choice (Motorised travellers using principally the car or Active travellers using mainly walking or cycling) classifying each Behavioural Group according to Table 4. In defining these groups, the desired behavioural and attitudinal position has been identified: as many travellers as possible need to be part of the shaded column: becoming 'Active Travellers' and ideally Sustainably Aspiring Active Travellers to encourage sustainable behaviours in the long term and across the spectrum of behaviours (i.e. not just travel). Where behavioural shifts may not be possible to achieve this, addressing current travel behaviour patterns would provide an opportunity to encourage sustainable travel without attempting to change attitudes.

\begin{tabular}{|l|l|l|l|}
\cline { 3 - 4 } \multicolumn{2}{c|}{} & \multicolumn{2}{|l|}{ Behaviour } \\
\cline { 3 - 4 } \multicolumn{2}{c|}{} & Active Traveller & Motorised Traveller \\
\hline \multirow{2}{*}{\begin{tabular}{l} 
Sustainable \\
\multirow{2}{*}{\begin{tabular}{l} 
Aspirer \\
\cline { 2 - 4 }
\end{tabular}}
\end{tabular}} & $29.8 \%$ & $43.9 \%$ \\
\cline { 2 - 4 } & $\begin{array}{l}\text { Environmental } \\
\text { Apathetic }\end{array}$ & & $26.3 \%$ \\
\hline
\end{tabular}

Table 4. Attitudinal and behavioural split of individuals.

The attitude-behaviour gap identified in this research confirms that sustainable intentions are not always translated into corresponding travel behaviour and unsustainable intentions are not always translated into unsustainable travel behaviour. This is true of the Environmental Apathetics who represent $29.4 \%$ of the Sustainably Aspiring Active Travellers. This brings to light that the perceived behavioural controls (or perceived barriers to travel behaviour change) are not exclusive to one attitude type (i.e. Sustainable Aspirers) and therefore an approach focussed more specifically on 
the barriers common to all Attitude and Behavioural groupings will be most effective in addressing this two-way attitude-behaviour discrepancy. It is also crucial to acknowledge that group segmentation for behaviour change should address identified barriers to change and should be flexible with a primary aim of encouraging more sustainable travel choices and secondly, to maximise the sustainability of travel choices should a shift in behaviour not occur or not be possible.

\section{Addressing perceived barriers to travel behaviour change}

Focus group discussions provided in depth details of reasons for lack of adoption of alternative travel choices; these related to the individual and systems levels and should therefore be taken into consideration simultaneously to support and influence long term sustain sustainable travel.

\section{Inadequate alternative options}

Frustration exists regarding the perception that people are pressured into changing their behaviour yet there is not a suitable public transport system in place to support their travel needs. The cost of public transport is considered unbalanced in light of the effort that is required: the convenience, comfort and time saving qualities of personal car use come across as being unparalleled when compared to the public transport system. Factors such as cost, convenience, journey time, habit and the lack of transparency at the individual level add to this and help explain why reductions in personal car use are not pursued. 
'You have to make it cost effective, if it's no cheaper than driving, people will drive; if it's inconvenient then people won't do it. You have to think about it and join it up.' (Participant 33)

'I would take the train to work but it's too expensive.. I don't think people are going to change when it's costing them more to do the alternative'. (Participant 30)

'Nobody's going to buy these Prius when they come up for second hand use as the Lithium batteries cost $£ 10,000$ to replace! Only Hydrogen fuel cells would work, they only emit $\mathrm{H}_{2} \mathrm{O}$.' (Participant 16)

In order to increase sustainable travel choices, a reduction in car use is required yet there is a clear belief that there is not a system in place to support the travel and quality needs of each individual. The influence of social norms at this stage is evident where there is widespread belief that, until alternative transport options are adequate, a shift away from personal travel by car is highly unlikely. In order to accommodate this need, public transport, for example, does not need to undergo a significant re-development, instead perceptions towards it must be altered: respondents are requesting an attractive, economically viable, time efficient, and frequent system, and in order to satisfy their requirements and influence them to select sustainable options, these must be considered. 
'I got knocked off my bike and I haven't been back on a bike since. It put me off cycling. What more could I have done? I was entirely visible... There isn't a cycle network in Southampton.' (Participant 12)

'Where I live you can't live if you don't have a car, even though I only live 4 miles from Havant. We've tried to bike but we still have to have a car.' (Participant 18)

Incentives and penalties

A major inhibitor of behaviour change appears to be the lack of financial enforcement and incentives; respondents recognise that financial penalties are more likely to lead to behaviour change if these reflect the environmental cost of travel. The strongest means of ensuring the intended behaviour is realised is to directly impose a financial penalty on travellers which can take the form of a tax for the vehicle used is based on the distance travelled whilst informing individuals of the reduced costs of other methods of travelling.

'Nothing hurts more than when it affects the wallet.' (Participant 2)

'When fuel prices in the UK went up last year, people's behaviour actually changed, the only time people changed their behaviour is when it hit their pocket ... Make an option that's cheaper and more convenient, but if there's an environmental benefit as well that makes 
them feel good about it and I think they will do that'. (Participant 30)

'High tax on my car is making me drive less personally - but l'm not confident the bus system is adequate for my needs.' (Participant 3)

The role of habitual travel

Unsustainable habit enforced by inadequate alternative options is an issue widely recognised as being part of respondent's current lifestyles and appears this is perceived as the accepted norm. The need to travel is at times perceived as unchangeable and often is incorporated into habitual routines which are also perceived as being as efficient and sustainable as possible.

'People used to work locally. Everything changed now, everything is a commute. How do you stop the need for people to travel? I go to evening classes twice a week and I take the car. (...) And there isn't much that's going to stop me doing that really...' (Participant 21)

The car is perceived as an invention which provides overwhelming control, independence, freedom and personal space, a medium to escape the world whilst providing flexible transport mode which is often perceived as a lot more convenient, faster, and economical. For these reasons, people do not want to give it up; asking to reduce its use, for something like the environment, is perceived as an infringement of basic rights and stripping travellers of a basic necessity. 
'I motorcycle and I can go a lot further than if I were in a car, simply because it's very light and it's very efficient. I'm doing my best, I'm doing what I can (...), I don't do what I do for environmental reasons, I do it for economic reasons. I can't afford to waste energy.' (Participant 13)

A series of preferences at the individual level determine the use and re-use of transport modes and sustainable travel practices, these encompass: adequacy, efficiency, convenience, comfort, travel time, cost benefits of use and sufficient facilities to support these (i.e. cycling facilities). Whilst these may in fact be catered for by local government, longstanding disdain for the use of other transportation modes means that embedded opinions continue to control the exploration of new travel modes. Responses showed that inadequate information of alternative available options enhanced negative feelings for public transport and that providing up to date and easy to access information on these services could significantly increase their use.

The need for an integrated holistic approach for sustainable travel behaviour

An integrated and systemic approach is required where all involved (whether it be local authorities, bus operators, local businesses and so forth) work simultaneously to achieve the objective of increasing sustainable travel behaviour. Where changes at the individual level are encouraged in terms of (i) a reduction in travel by car and switching to more sustainable means of transport, or (ii) adoption of more sustainable travel practices when reductions in car use are not possible, the potential or change in travel behaviour will be maximised if aligned with and supported by policies, 
legislation, infrastructure at the local level. Initiatives in Ghent, Belgium; Brittany, France and Norfolk, Sutton and wider parts of the UK provide examples of the successes of a holistic approach which incorporates a personalised information system addressing identified behaviours and increasing awareness of alternative travel choices available.

A holistic approach is required both for the facilitation of shifts to more sustainable travel practices as well as to highlight the benefits to each involved. Benefits can be widespread and sustained in the long term with evidence from other cities demonstrating increased accessibility, increased employment, increased health and well-being, an increased integrated transport system, increased personal engagement, reduced congestion, reduced air pollution and public involvement and engagement in local economic growth.

\section{Conclusion}

Travel behaviour schemes have demonstrated significant potential in delivering sustainability at the local level, yet these schemes do not fully recognise that travel decisions are unique and are made at the individual level embedded in the specific context within which the traveller is located. Travel is not only valued for its purpose but it is increasingly valued for its recreational qualities calling for a need to tackle behaviour change at the psychological level in addition to within transport infrastructure. This paper has explored the role of travel behaviour in addressing this and demonstrated how travel behaviour programmes can be utilised at the local level to increase sustainable travel patterns. This also simultaneously addresses other issues that surround 
automobility such as unemployment, accessibility, health and local air pollution. The UK has a commitment to reduce its $\mathrm{CO}_{2}$ emissions by $60 \%$ below 1990 levels by 2050 and with local authority activities contributing to climate change they have a key role in adaptation and prevention of the issue through their local climate change adaptation and sustainable transport plans.

Local government is in a unique position to lead on individual targeting based on attitudes and behaviour in order to overcome perceived barriers to changes in travel behaviour. This paper identified key audiences to target based on age, awareness and attitude and has classified individuals according to three behavioural groupings: Environmentally Apathetic and Sustainably Aspiring Motorised Travellers as well as Sustainably Aspiring Active Travellers. Addressing the current patterns and needs of these groupings by fully utilising and publicising the existing local transport network and increasing intentions to travel more sustainably is well within the capabilities of local government. Focus group discussions highlighted that the principal barriers to uptake of sustainable travel options such as public transport where (i) inadequacy of alternatives in terms of costs and efficiency, (ii) habitual behaviour and (iii) and lack of financial penalties and incentives. A holistic approach is therefore needed where both the individual and the 'system' work in unison to ensure the means of the traveller are met and that these are in line with what is available and in line with local government targets.

This paper investigated the sustainable side of automobility by addressing sustainable travel behaviour in two ways, primarily by increasing adoptions of more sustainable choices at the individual level (e.g. increased use of public transport), ensuring support at the systems level is in 
line with behavioural aspirations, and where shifts in transport choices are not possible to focus on increasing sustainable travel practices (e.g. smart driving). An overview of existing and past sustainable transport initiatives was provided and clear population segmentations were derived based on attitudes and behaviour with barriers around uptake of sustainable travel choices as key enablers of future change. Further research is now needed to apply these population segmentations at the local level adopting a holistic approach where both the needs and barriers of the individual and the local 'system' are addressed to increase the social, environmental and economic sustainability of local automobility.

\section{Acknowledgments}

Part of this research was funded by the Department for Transport and the Engineering and Physical Sciences Research Council. The authors would also like to thank the two reviewers for their valuable comments.

\section{References}

Ajzen, I. (1991) The Theory of Planned Behaviour. Organizational Behaviour and Human Decision Processes, 50, pp179-211.

Ampt E and Rooney A (1998) Reducing the Impact of the Car - A Sustainable Approach: TravelSmart, Adelaide. Paper prepared for the $22^{\text {nd }}$ Australasian Transport Research Forum, Sydney, Australia, September 1998. 
Avineri E and Goodwin P (2010) Individual Behaviour Change: Evidence in transport and public health. The Department for Transport, London: UK.

Banister D, Pucher J and Lee-Gosselin M (2007) Making Sustainable Transport Politically and Publicly Acceptable, in Rietveld P and Stough R (eds) Institutions and Sustainable Transport: Regulatory Reform in Advanced Economies. England: Edward Elgar Publishing, pp. 17-50.

Besser L and Dannenberg A (2005) Walking to public transit - steps to help meet physical activity recommendations. American Journal of Preventive Medicine, 26(4).

Bongardt D, Breithaupt M and Creutzig F (2010) Beyond the fossil city: Towards low carbon transport and green growth, EST Background Paper, Eschborn: Germany.

Brög W, Erl E, and Mense N (2002) Individualised Marketing: Changing Travel Behaviour for a better Environment. Paper presented at the OECD Workshop: Environmentally Sustainable Transport, Berlin, December 2002.

Bulkeley H and Kern K (2006) Local Government and the Governing of Climate Change in Germany and the UK. Urban Studies, 43(12): 2237-2259.

Cabinet Office (2009a) The wider costs of transport in English urban areas. Cabinet Office, The Strategy Unit. Available online at http://webarchive.nationalarchives.gov.uk/+/http://www.cabinetoffice.gov.uk/media/307739/widercosts-transport.pdf

Cabinet Office (2009b) An analysis of urban transport. Cabinet Office, The Strategy Unit. Available online at 
http://webarchive.nationalarchives.gov.uk/+/http://www.cabinetoffice.gov.uk/media/308292/urbantra $\underline{\text { nsportanalysis.pdf }}$

Carr M, Lund T, Oxley P and Alexander J, 1994, Cross-Sector Benefits of Accessible Public Transport. Transport Research Laboratory Report 39: Cranfield University.

Cairns S, Sloman L, Newson C, Anable J, Kirkbride A and Goodwin P (2008) Smarter Choices: Assessing the Potential to Achieve Traffic Reduction Using 'Soft Measures'. Transport Reviews, 28 (5): 593-618.

Commission for Integrated Transport (2006) Integrated Transport Delivery - Is it working across Government Departments? Commission for Integrated Transport.

Cooper C. (2007) Successfully Changing Travel Behavior: Applying Community-Based Social Marketing to Travel Choice. Transportation Research Record: Journal of the Transportation Research Board, 2021: 89-99.

Defra (2010) National Indicator 188: Adapting to climate change. Available online at http://www.defra.gov.uk/corporate/about/with/localgov/indicators/ni188.htm. Accessed 9/11/2010

Department for Transport (2005) Making Campaigning for Smarter Choices Work. Guidelines for Local Authorities. TAPESTRY, May 2005.

Department for Transport (2006) The Eddington Transport Study. The case for action: Sir Rod Eddington's advice to Government. The Stationery Office, London: UK.

Department for Transport (2009) Transport Trends: 2008 edition. The Stationery Office, London: UK. 
Department for Transport (2011) Creating Growth, Cutting Carbon. Making Sustainable Local Transport Happen. Crown Copyright, The Stationery Office, London: UK.

Department for Transport / ONS (2008) Public attitudes to climate change and the impact of transport: 2006, 2007, 2008. The Department for Transport, London: UK.

Department of Trade and Industry (2005) Digest of UK Energy Statistics 2005. The Stationery Office, London: UK.

Douglas M, Thomson H, Jepson R, Hurley F, Higgins M, Muirie J, Gorman D (eds) Health Impact Assessment of Transport Initiatives: A Guide, NHS Health Scotland, Edinburgh: Scotland.

Environmental Audit Committee (2006) Reducing Carbon Emissions from Transport. Ninth Report of Session 2005-2006. The Stationery Office Ltd, London: UK.

Euro Barometer (2011) European's attitudes towards climate change. Special Euro Barometer 313, Directorate General of the European Commission, Brussels: Belgium.

European Commission (2011) White Paper - Roadmap to a Single European Transport Area Towards a competitive and resource efficient transport system.

European Environment Agency (2010) Towards a Resource-Efficient Transport System. TERM 2009: indicators tracking transport and environment in the European Union. EEA Report 2/2010, Copenhagen: Denmark.

European Federation for Transport and Environment (2007) Regulating $\mathrm{CO}_{2}$ emissions of new cars. Brussels: Belgium.

Fujii S and Gärling T (2007) Role and Acquisition of Car-Use Habit. In Threats from Car Traffic to the Quality of Urban Life, Gärling T and Steg L (Eds). Elsevier Ltd, Amsterdam: The Netherlands. 
Fujii S and Taniguchi A (2006) Determinants of the effectiveness of travel feedback programs a review of communicative mobility management measures for changing travel behaviour in Japan. Transport Policy, 13: 339-348.

Gore E and Parckar G (2009) Disability and the Downturn, Leonard Cheshire Disability, London: UK.

Gore E and Parckar G (2010) Rights and Reality: Disabled people's experience of accessing goods and services, Leonard Cheshire Disability, London: UK.

Gorman D, Douglas MJ, Conway L, Noble P and Hanlon P, . 2003, Transport policy and health inequalities: a health impact assessment of Edinburgh's transport policy. Public Health, 117: 15-24.

Greene DL and Wegener M (1997) Sustainable transport. Journal of Transport Geography, 5(3): 177-190.

Davis A and Cavill N, 2005, Making the Case: Improving health through Transport Health Development Agency

Howarth C (2010) Perceived Barriers to Sustainable Travel Behaviour Change and the Role of Information on Climate Change. PhD Thesis, University of Southampton, UK.

Howarth C and Ryley T (2012) Chapter 10: A behavioural perspective on the relationship between transport and climate change. In Ryley T and Chapman L (Eds) Transport and Climate Change. Emerald

Howarth C, Waterson B, McDonald M. (2010) Perceived behavioural control and the role of information on climate change in increasing sustainable travel. $41^{\text {st }}$ Annual University Transport Study Group Conference, 5-7 ${ }^{\text {th }}$ January 2010, Plymouth: UK. 
International Environmental Agency (2001) Saving Oil and Reducing $\mathrm{CO}_{2}$ Emissions in Transport, Options and Strategies. OECD. Paris: France.

Kay D, Reynolds J, Rodrigues S, Lee A, Beverley Anderson B, Gibbs R, Monkhouse C and Gill T, (2011) Fairness in a Car-dependent Society, Sustainable Development Commission Report

Laidler A, Greenhalgh C, Parckar G, Foster J, Hough M and Knight J Disability Review 2007, Leonard Cheshire Disability, London: UK.

Lorenzoni I, Nicholson-Cole S, Whitmarsh L (2007) Barriers perceived to engaging with climate change among the UK public and their policy implications. Global Environmental Change, 17: 445459

Polyviou P, Hounsell NB and Shrestha BP (2012) Modelling Incidents for Dynamic Bus Fleet Management Purposes: A UK perspective, Transportation Planning and Technology, 35(1): 49-67

Sloman L, Cairns S, Newson C, Anable J, Pridmore A. and Goodwin P (2010) The Effects of Smarter Choice Programmes in Sustainable Travel Towns: Summary Report. Report to the DfT

Social Exclusion Unit (2003) Making the Connections: Final Report on Transport and Social Exclusion. Crown Copyright, London: UK.

Society of Motor Manufacturers and Traders (2009) Vehicle Production Figures. Press Release 4715, 23 October 2009.

Stradling SG (2003) 'Reducing Car Dependence'. In: Hine, J., Preston, J. (Eds) Integrated Futures and Transport Choices: UK Transport Policy beyond the 1998 White Paper and Transport Act. Ashgate, Aldershot, UK, p100-115. 
Transport and Travel Research Ltd (2005) Tapestry: Deliverable 6. Results and Recommendation. Available online at http://www.eltis.org/docs/tapestryoverview.pdf

Transport for London (2010) Third Annual Report 2010. Smarter Travel Sutton. Mayor of London, Sutton, TfL.

UK Department for Transport (2009) Public Transport Statistics Bulletin GB: 2009 edition. The Stationery Office, London: UK.

UK Sustainable Development Commission, 2010. Smarter Moves: How Information Communications Technology can promote Sustainable Mobility.

Wood C. and Grant E (2011) 'Tracking the lives of disabled families through the cuts...' Destination Unknown, Spring 2011. London: Demos. 